\title{
Co-exploring the Water-Energy-Food Nexus: Facilitating Dialogue through Participatory Scenario Building
}

\author{
Oliver W. Johnson ${ }^{1 *}$ and Louise Karlberg ${ }^{2}$ \\ ${ }^{1}$ Stockholm Environment Institute, Nairobi, Kenya, ${ }^{2}$ Stockholm Environment Institute, Stockholm, Sweden
}

OPEN ACCESS

Edited by:

Tuyeni Heita Mwampamba, National Autonomous University of

Mexico, Mexico

Reviewed by:

Indira Devi Puthussery,

Kerala Agricultural University, India

Joseph Sang,

Jomo Kenyatta University of

Agriculture and Technology, Kenya

${ }^{*}$ Correspondence:

Oliver W. Johnson

oliver.johnson@sei-international.org

Specialty section:

This article was submitted to Agroecology and Land Use Systems,

a section of the journal

Frontiers in Environmental Science

Received: 24 December 2016 Accepted: 05 May 2017

Published: 24 May 2017

Citation:

Johnson OW and Karlberg L (2017) Co-exploring the Water-Energy-Food

Nexus: Facilitating Dialogue through Participatory Scenario Building.

Front. Environ. Sci. 5:24

doi: 10.3389/fenvs.2017.00024
The "water-energy-food nexus" has become an increasingly popular way to frame the challenges associated with reconciling human development objectives with responsible management of natural resources and ecosystems. Yet the nexus is complex, requiring effective engagement between expert and Non-expert stakeholders in order to understand biophysical inter-linkages between resources and resource flows and social interactions between different actors in the socio-ecological system and landscape. This can be a substantial challenge due to varying levels of knowledge and understanding amongst actors with divergent, and often entrenched, interests. This paper presents insights on how participatory scenario-building processes can create space for dialogue amongst stakeholders with differing knowledge, experience, priorities, and political perspectives. Drawing on completed and on-going research applying a "nexus toolkit" in Ethiopia and Rwanda respectively, we contribute to a generalized conceptual framework for addressing, communicating, and assessing the water-energy-food nexus, with a particular focus on how to utilize the nexus concept in practice. This framework has significant potential to help better understand interactions at landscape level, for example, between charcoal production, food production, and environmental systems. We find that participatory scenario-building processes that facilitate engagement beyond technical aspects to include social, economic and political concerns provide a valuable space for discussing and negotiating development pathways that are sustainable both biophysically and socio-economically. In addition, the involvement of stakeholders throughout the project process greatly enhances the quality and legitimacy of results. Furthermore, we suggest that by building capacity amongst stakeholders to maintain a quantitative "nexus toolkit," it has a better chance of informing decision-making and for supporting the development of more technically refined analyses of alternative decisions and management strategies.

Keywords: water-energy-food nexus, scenario planning, stakeholder dialogue, co-exploration, Ethiopia, Rwanda

\section{INTRODUCTION}

In recent years, the "water-energy-food security nexus" has become an increasingly popular way to frame the challenges associated with reconciling human development objectives with responsible management of natural resources and ecosystems (Bazilian et al., 2011; Hoff, 2011; Howells et al., 2013). The value of the "nexus" concept lies is its ability to clarify inter-linkages and 
competition for resources between different sectors of the economy and highlight the implications on development of (un)coordinated decision-making and management in these sectors. Therefore, a nexus approach is useful when there is a need to plan and govern interdependent resource-related matters, for instance, when different sectors depend on the same resources or the direct inputs from each other. In low-income countries, this pertains to hydropower generation, irrigation, fodder production, manure management, and the charcoal sector. In the latter case, a nexus analysis is of specific relevance given the complex interactions between the charcoal sector and deforestation, ecosystems, energy use, and income generation (see Chidumayo and Gumbo, 2013; Mwampamba et al., 2013; Zulu and Richardson, 2013).

The intrinsic complexity of the "nexus," particular in relation to the charcoal sector, underlines the need for effective engagement between expert and non-expert stakeholders in order to understand biophysical inter-linkages between resources and resource flows and social interactions between different actors in the socio-ecological system and landscape. Stakeholder engagement is also essential for building dialog and negotiating solutions around how to better coordinate decision-making and management across sectors for the purpose of sustainable and equitable development. However, achieving effective engagement between expert and non-expert stakeholders can be a substantial challenge due to varying levels of knowledge and understanding amongst actors with divergent and often entrenched, interests, and power to influence decision-making.

This paper presents insights on how participatory scenario-building processes can create space for dialog amongst stakeholders with differing knowledge, experience, priorities, power, and political perspectives. In doing so, we contribute to a generalized conceptual framework for addressing, communicating, and assessing the water-energy-food nexus, with a particular focus on how to utilize the nexus concept in practice to better understand challenges faced in the charcoal sector. To illustrate insights on how participatory scenario-building processes can help to illuminate particular nexus contexts in reality and create space for dialog on solutions to more integrated development pathways, we draw on completed and on-going action research projects in Ethiopia and Rwanda respectively. In these projects, we utilized a quantitative "nexus" toolkit, based upon the dynamic linking of a water and biomass modeling software tool-Water Evaluation and Planning (WEAP) - with an energy and climate modeling software tool-Long-range Energy Alternatives Planning (LEAP).

\section{THE FOOD-ENERGY-WATER NEXUS CHALLENGE IN SUB-SAHARAN AFRICA}

Many countries across Sub-Saharan Africa are witnessing rapid growth and development, largely driven by the processes of energy transition and agricultural transformation (Africa Progress Panel, 2015; AfDB, 2016). Sustainable energy transitions involve moving away from traditional biomass use to more modern energy services, ensuring universal access to reliable electricity supply, all whilst meeting climate change mitigation goals. Options may include modern bioenergy and hydropower, both of which require access to water and land resources. Meanwhile, agricultural transformation typically refers to improved productivity through intensification and commercialization, as well as integration into world markets. Such transformation is likely to require significantly higher energy and water inputs to improve productivity. At the same time, withdrawal of water upstream for irrigation purposes may reduce the water available for hydropower generation and ecosystems. A changing climate places further emphasis on the need to effectively manage water resources to adapt to and minimize the impacts of more frequent droughts. These changes, in addition to population increases and shifting patterns of consumption, lead to greater demand for natural resources and ecosystem services (Hallding et al., 2012; Jäger and Patel, 2012; Bierbaum et al., 2014). These pressures are exacerbated by the impacts of climate change, potentially leading to degradation of resources and leaving many millions of people food, energy, and water insecure (Matthew et al., 2010; Lee et al., 2012).

The future of charcoal production, trade and use is closely connected to processes of energy transition and agricultural transformation. Increased use of charcoal in urban centers in sub-Saharan Africa complicates attempts to facilitate an energy transition to cleaner low-carbon energy services: over $80 \%$ of urban households in the region rely on charcoal as their main source of cooking, and demand is set to increase as population grows and urbanization continues (Zulu and Richardson, 2013). At the same time, the clearing of forest to make way for agricultural land often provides opportunities for charcoal production using cleared forest resources (Mwampamba et al., 2013). The environmental and ecosystem impacts of charcoal production-whether from forest resources cleared for agricultural production or otherwise-can be severe (Chidumayo and Gumbo, 2013).

Within Sub-Saharan Africa, Ethiopia, and Rwanda stand out as two countries with ambitious development plans based around transforming agriculture and energy transition. Although, vastly different in terms of geographical size and population, both countries show similarities in their GDP per capita, percentage of the population employed in agriculture and energy access rates (see Figure 1).

Ethiopia has ambitions to become a middle-income country by 2025 . A variety of targets have been set to help it reach this goal, including a number related to the agriculture and energy sectors. In 2010, the Government of Ethiopia established the Growth and Transformation Plan (GTP) followed by the Climate-Resilient Green Economy (CRGE) strategy in 2012 (Ministry of Finance and Economic Development, 2010; Federal Democratic Republic of Ethiopia, 2012). Both policy documents describe a pathway toward developing and modernizing the national economy in a sustainable, climate-compatible manner.

Ethiopia's GTP and GTP II targets build on long-standing agriculture growth and set targets associated with agricultural inputs (such as improved seeds, fertilizer, mechanization, land), energy generation (hydropower), irrigation, conservation, and land use. For example, by converting grazing and/or forest 

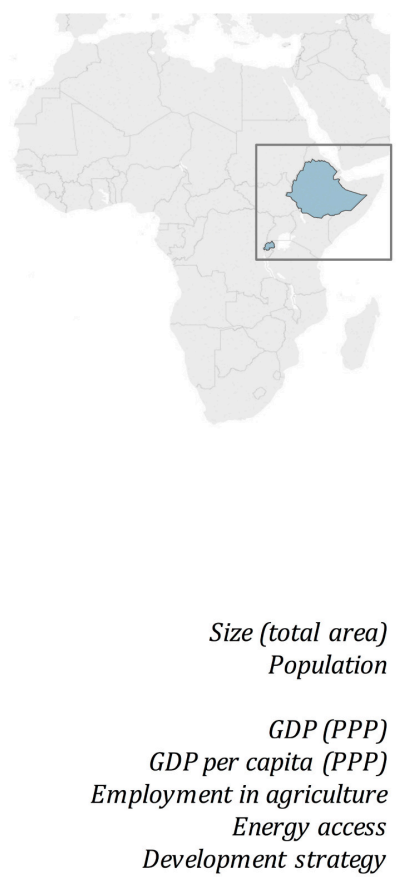

Green growth strategy

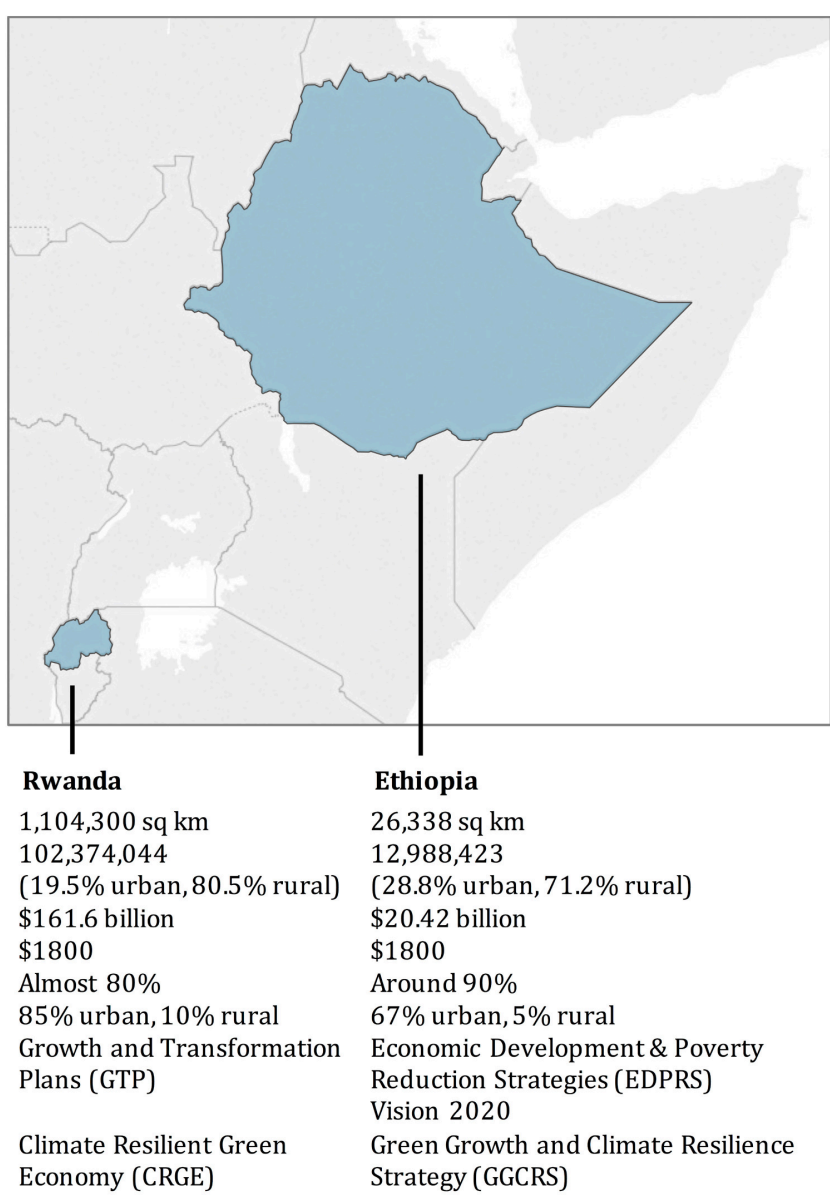

$\begin{array}{ll}\text { Climate Resilient Green } & \text { Green Growth an } \\ \text { Economy (CRGE) } & \text { Strategy (GGCRS) }\end{array}$

FIGURE 1 | Country comparison. CIA World Facebook (CIA, 2016).

land into cropland, the government aims to achieve a 13 per cent increase in cultivatable land. Meanwhile, irrigated land is expected to increase by more than 400 per cent during the same time period. Lastly, fertilizer use is projected to increase by roughly 100 per cent, leading to dramatic increases in productivity and agricultural output: e.g., increasing crop productivity by 30 per cent, power generation by 300 per cent, and sugar production by 600 per cent (Ministry of Finance and Economic Development, 2010).

As well as these conventional economic growth objectives, GTP also sets out a National Resource Conservation Plan that aims to rehabilitate land and increase forest cover. The CRGE strategy-which aims to ensure ambitious national development plans are not adversely affected by climate changefurther describes these conservation targets (Federal Democratic Republic of Ethiopia, 2012). While the targets set out in the CRGE strategy-shown in Table 1-are admirable, it is unclear whether all direct impacts or potential conflicts between targets have been adequately explored. For example, there is little to suggest that conflict between water use for irrigation and hydropower development has been studied. Similarly, continued and increasing exploitation of forest resources for charcoal production and construction purposes may make it increasingly difficult to meet forest cover targets. By 2014, over three million tonnes of charcoal were being consumed each year in Ethiopia's urban centers; as in many countries in sub-Saharan Africa, attempts to regulate charcoal production and trade to make it more sustainable have been ineffective (Bekele and Girmay, 2014). Considering and pre-empting such conflicts is particularly important when analyzing potential welfare impacts, preparing coping mechanisms, and managing environmental feedback effects at the local level.

Furthermore, the rapid expansion of hydropower and irrigation infrastructure has heightened tensions with neighboring countries that depend extensively on water resources originating from the Ethiopian highlands for household, agricultural, and industrial consumption. Yet it also signals a changing geopolitical climate in which Ethiopia is becoming an important force in the Horn of Africa region (Rahmato, 2011; Verhoeven, 2011). Given these related concerns, it is unlikely that all the goals of the GTP and the CRGE can be met simultaneously, particularly when following a conventional sectoral approach (Karlberg et al., 2015a).

Meanwhile, Rwanda has committed itself to becoming a middle-income country by 2020. The countries Vision 2020 and Economic Development and Poverty Reduction Strategies 
TABLE 1 | Green growth strategies in Ethiopia and Rwanda.

\begin{tabular}{|c|c|c|}
\hline Issue areas & Ethiopia's CRGE & Rwanda's GGCRS \\
\hline \multirow[t]{2}{*}{$\begin{array}{l}\text { Land and agricultural } \\
\text { transformation }\end{array}$} & $\begin{array}{l}\text { Improving crop and livestock production practices for higher } \\
\text { food security and farmer income while reducing emissions }\end{array}$ & $\begin{array}{l}\text { Ensuring sustainable land-use and natural resources } \\
\text { management resulting in food security and the preservation } \\
\text { of biodiversity and ecosystem services }\end{array}$ \\
\hline & $\begin{array}{l}\text { Safeguarding forests and reforestation in order to maintain } \\
\text { their economic and ecosystem services, including as } \\
\text { carbon stocks }\end{array}$ & \\
\hline \multirow[t]{2}{*}{ Energy transition } & $\begin{array}{l}\text { Increasing electricity supply from renewable sources for } \\
\text { domestic and regional markets }\end{array}$ & $\begin{array}{l}\text { Achieving energy security and low carbon energy supply, } \\
\text { while avoiding deforestation }\end{array}$ \\
\hline & $\begin{array}{l}\text { Leapfrogging to clean, efficient and modern and } \\
\text { technologies in transport, industrial sectors, and buildings }\end{array}$ & \\
\hline Societal impacts & & $\begin{array}{l}\text { Societal protection, including reduced vulnerability to } \\
\text { climate change }\end{array}$ \\
\hline
\end{tabular}

Federal Democratic Republic of Ethiopia (2012); Republic of Rwanda (2011).

(EDPRS I and II) both set out clear intentions to intensify agriculture and increase national energy output (Republic of Rwanda, 2013, 2007). For example, agriculture is expected to grow by $8.5 \%$ annually and energy generation is expected to grow from $45 \mathrm{MW}$ in 2006 to $563 \mathrm{MW}$ in 2018, mainly through development of hydropower. These ambitions are also present at a sub-national level, with District Development Plans including provisions to modernize agriculture, invest in energy production and expand many water-intensive activities, such as mining, industrial development, and ecotourism.

These development goals place increasing pressure on limited water and biomass resources. Competition over water resources demanded by hydropower, irrigation, and water supply to major towns and various industries has the potential to create serious conflict. Meanwhile, biomass scarcity causes the country to import biomass from neighboring countries as well as having to allocate croplands to wood plantations, such as eucalyptus; in $2009,21 \%$ of the biomass consumption was ascribed to unsustainable use of biomass and "the constant flow of charcoal into Kigali, exerts a considerable pressure on the wood resources of the country" (Drigo et al., 2013, p. vii). In addition, an intensified agricultural sector will demand more energy and water per hectare, although a modernized energy sector less dependent on traditional biomass is likely to be less landintensive.

In order to better understand the linkages between different sectors in future scenarios, Rwanda developed its Green Growth and Climate Resilience Strategy (GGCRS) in 2011 (Republic of Rwanda, 2011). The GGCRS was developed to guide decisions around natural resource management, investments and policy as well establish demonstration initiatives to support climate resilience activities and community livelihoods. The GGCRS centers around three cornerstones, shown in Table $\mathbf{1 .}$

Whilst green growth and development plans in Ethiopia and Rwanda appear impressive-and have garnered significant support from international development partners (The Economist, 2010)—these ambitious national plans raise a number of concerns. In both countries, the political reality is complex. Despite exhibiting the formal institutions of democracy, civil society remains "stunted" (Matfess, 2015). Political opposition in Ethiopia is weak (Kefale, 2011) and the failure to meaningfully engage stakeholders at all levels of society, particularly at the local level, raises key issues of equity, representation, and recognition. This is likely to further exclude those who are already politically and socially marginalized (Jones and Carabine, 2013). There have been impressive efforts in Rwanda to reconstruct and modernize the country after genocide (Uvin, 2001; Ansoms, 2008), including huge steps to achieve better gender equality in political representation, with women taking 64 per cent of parliamentary seats in 2013 (United Nations, 2013). However, citizen participation is low in areas such as policy making, formulation of laws, decision-making and development, and evaluation of local government programmes (Interayamahanga, 2011). Decentralization has not increased the voice of local people, but has merely allowed the central level to extend its influence to the local level (Ansoms, 2008). This "developmental authoritarianism" (Matfess, 2015) reduces the prospects for democratic deliberation over green growth strategies and plans and the potential for developing alternative pathways and understandings of "sustainability."

Taken together, these issues point to the need for approaches that can "open up" space for dialog in order to deal with complex nexus issues. Such approaches need to be based on quantitative assessments of resources availabilities, as well as qualitative analysis of the impacts on whole socio-economic systems. Our goal is to develop, test and apply such an approach through a process of collaborative stakeholder dialog.

\section{PARTICIPATORY SCENARIO BUILDING APPROACH FOR CO-EXPLORING THE NEXUS}

The inherent complexity of the water-energy-food nexus approach makes stakeholder participation essential, particularly if space is to be opened up for actors with different perceptions 
to be heard, particularly those who are often marginalized. One way to open up space for co-exploration and dialog around nexus issues is through a participatory scenario-building approach, combining qualitative, and quantitative methods.

\section{Scenario Building for the Water-Energy-Food Nexus}

Scenario building is becoming widely appreciated as an effective way in which to explore interactions between complex social and environment systems over the medium-to-long term (Swart et al., 2004; Kok et al., 2007; Volkery et al., 2008). Essentially, scenario building is a way to posit ideas about the future, with scenarios describing how the future may develop based on a certain set of assumptions about potential drivers of change and uncertainties (Bradfield et al., 2005; Millennium Ecosystem Assessment, 2005). Exploratory scenarios are particularly relevant for investigating the water-energy-food nexus, as it allows us to explore development pathways arising from the interactions between different sectoral strategies.

Exploratory scenarios can be qualitative, quantitative ormore often than not-a mix of the two. Often a "story and simulation approach" (Alcamo, 2008) is pursued whereby qualitative scenarios-storylines or narratives-describing the broader picture of future development are quantified for use in computer-based modeling tools. Typically, each scenario represents a possible future state of the social and environmental system under consideration (Spielmann et al., 2005).

Exploratory scenarios can also be used at different levels. For example, at the global level, scenarios were used in the IPCC Special Report on Emissions Scenarios (SRES; Nakicenovic et al., 2000) and in Shared Socioeconomic Pathways (SSPs; O'Neill et al., 2015), the new scenario process replacing the SRES scenarios. On the local level there are numerous studies employing scenario planning, e.g., climate adaptation planning (Baard et al., 2011; Carlsen et al., 2013), integrated water resource management (Voinov and Gaddis, 2008) and governance of sustainable development (Bohunovsky et al., 2011).

\section{Participation and Engagement}

Building scenarios can be done in many ways. Typically scenarios are constructed by developing a storyline or narrative (as in the story and simulation approach), based around first prioritizing the most uncertain and most important driving forces. These driving forces might encompass trends associated with population growth, economic growth and urbanization, potential changes in climate and planned policies, and interventions. Given the unlimited range of scenarios that can be developed, it often makes sense to narrow down to a small number of particularly relevant scenarios based upon broad plausible storylines/narratives. A typical starting narrative is the "business-as-usual" scenario, whereby the key drivers affecting future development are on-going demographic trends, such as population growth, economic growth, and increasing urbanization. Other scenarios may be based upon the implementation of planned national polices and interventions, or on certain climate change projections.
This leads to key questions around who defines the storyline, and whose voice is represented in this version of the future? Who decides which driving forces are most important? The water-energy-food nexus presents a particular challenge given the complex inter-linkages between sectors and the different future pathways identified with by actors in different sectors. Furthermore, quantifying a given future pathway for use in an analytical scenario building may place a bias on the views of technical experts over those of non-experts (e.g., practitioners, policy makers, and the public).

How might participation improve planning and decisionmaking processes? Fiorino (1990) identifies three main rationales for increasing participation. The first is substantive: the public's judgments about risk are equally sound, and sometimes better, than those of experts; hence, increasing participation can improve the outcomes of planning. From this perspective, participatory nexus scenario planning can help to increase knowledge and understanding of the water-energy-food security nexus in a particular context, particularly nuanced framing with multiple perspectives. Combining factual information and analytical techniques with "local knowledge and subjective perceptions" (Pahl-Wostl, 2002) "imagination and expertise" (Volkery et al., 2008) from different stakeholder groups can help to build consensus on the current conditions and key driving forces (Andersson et al., 2008) and lead to more accurate scenarios reflecting local realities (Patel et al., 2007; Reed et al., 2013).

The second rationale for participation is instrumental: decisions that involve citizens are seen as more legitimate; hence, increasing participation ensures better buy-in, which leads to better results. Increasing participation in nexus scenario building may help to ensure "that all stakeholder groups involved have a high degree of confidence" (Andersson et al., 2008). It is vital to ensure future scenario storylines are credible, legitimate and salient, particularly "with respect to personal beliefs, the equifinality of alternative development pathways, the validation and uncertainty of assumptions, stakeholder engagement in visions development, and participatory methods" (Rounsevell and Metzger, 2010). Making sure scenarios are relevant to stakeholder needs and priorities (Reed et al., 2013) may significantly increase the chances of buy-in to subsequent policy proposals based upon the nexus analysis (Robinson et al., 2011).

The third rationale is normative: the best judge of citizens' interests are citizens themselves, hence, increasing participation is the right thing to do. This normative drive for participation is derived from the need for dialog to clarify problems, identify unavoidable trade-offs and negotiate viable solutions to complex and uncertain environmental and societal problems (Patel et al., 2007; Voinov and Bousquet, 2010; Ravera et al., 2011). Participatory processes can help trigger conversations on future developments between stakeholders who might never typically engage with each other (Volkery et al., 2008). If managed effectively, such engagement can "increase the level of understanding between the various groups and therefore ameliorates the potential for future conflicts" (Andersson et al., 2008). 


\section{Challenges to Effective Participation}

Despite the allure of participatory scenario building approaches to co-explore and address water-energy-food nexus issues, there are significant challenges to ensuring participation is effective. There are many rungs on the ladder of participation; from token participation (consultation and informing) to full citizen power (partnership and control; Arnstein, 1969). Not all mechanisms that are considered "participatory" actually provide opportunities for full engagement. In some cases, stakeholder engagement is merely symbolic (Voinov and Bousquet, 2010).

Participation in nexus scenario building is made difficult by the complex issues involved, typically crossing multiple sectors beyond the knowledge of any one person. This difficulty may be amplified if the quantitative technical models used to build scenarios are inaccessible. Indeed, there is often a risk of overwhelming stakeholders (Robinson et al., 2011). Avoiding this risk requires considerable investment in time and resources to ensure that complex information and decisions are presented to non-technical stakeholders in an accessible way (Kok et al., 2007; van Vliet et al., 2010; Robinson et al., 2011).

Despite best efforts, there remains the risk of participatory processes being framed such that the range of options considered reflects the preferences of incumbent interests. In this sense, participation is used as a "technology of legitimation" (Harrison and Mort, 1998 in Stirling, 2007, p. 264). As Stirling (2007) argues, participatory processes do not inherently solve the problem associated with expert-led planning: the sensitivity to framing by powerful interests. In order to make a difference, participatory processes need to open up the decision space beyond the options preferred by those with the most power and influence. They need to better inform and determine the technical analyses, and uncover alternatives that might not otherwise be considered.

\section{Participatory Nexus Scenario Building in Ethiopia and Rwanda}

Given the potential benefits and pitfalls of participatory processes to understand and seek solutions to the water-energy-food nexus, it is important to design a structured-but flexible-process or method to effectively and sincerely engage with stakeholders as one moves between "story" and "simulation." In our research in Ethiopia and Rwanda, we sought to co-produce different plausible development scenarios with stakeholders. In Ethiopia, the geographical scope of our study was the Lake Tana subbasin $^{1}$, while the Akagera river basin formed the geographical scope of our study in Rwanda ${ }^{2}$. The scenario co-production process in each case study was used to create space for dialog amongst stakeholders with differing knowledge, experience, priorities and political perspectives on how to address challenges and opportunities pertaining to the nexus.

\footnotetext{
${ }^{1}$ https://www.sei-international.org/mediamanager/documents/Publications/SEIDB-2013-Nexus-Blue-Nile-Ethiopia.pdf.

${ }^{2}$ https://www.sei-international.org/mediamanager/documents/Projects/ FONERWA_Project_Flyer[2].pdf.
}

The process, shown in Figure 2, was based on a set of iterative steps consisting of engagement with technical and nontechnical stakeholders to identify the current state of affairs and posit scenarios about how the future might unfold, followed by quantitative modeling of these scenarios. In a workshop setting, stakeholders and the project team jointly developed the assumptions, populated the model with their own data and critiqued the results of the tool in an iterative approach until the model is deemed credible. Moreover, stakeholders analyzed the socioeconomic and environmental impacts of the results and compare them with the goals in national strategies and policies. Lastly, stakeholders participated in the formulation of new policies and technical innovations to be tested in the toolkit, thereby supporting the development of new interventions. Application of the "nexus tool-kit" in Ethiopia, including quantitative scenario modeling results on the waterenergy-food nexus in the Lake Tana region, are available (see Karlberg et al., 2015a). Scenario modeling in Rwanda is still on-going and thus results are not yet published.

\section{Initial Stakeholder Engagement and Model Development}

The first step of the process consisted of initial engagement with stakeholders to understand the current context and setting, and discuss initial narratives or storylines about the future. In both case studies, local project partner(s) invited stakeholders for broader stakeholder engagement, as well as to be part of a smaller technical team who were part of developing the quantitative tools. In Ethiopia, the local project partner was the Bahir Dar University, a prominent university in the case study region. In Rwanda, and our local partner was the Albertine Rift Conservation Society (ARCOS), a conservation NGO headquartered in Kigali.

A first workshop was held with the broader stakeholder group to introduce the water-energy-food nexus concept, map out actors and institutions, define current issues pertaining to the nexus, and finally to create initial scenario narratives. In Ethiopia, 40 stakeholders attended the this first workshop, with participation from, for instance, the Bureau of Water Resource Development, the Bureau of Agriculture, the Bureau of Energy and Mines, the Fisheries Association, Environment Protection, Land Administration and Use Bureau, the Abbay Basin Authority, and Bahir Dar University. In Rwanda, around 25 stakeholders attended, representing the Ministry of Natural Resources, the Rwanda Natural Resources Authority, the Ministry of Agriculture, the Ministry of Local Government and the three districts specifically targeted in the study. In both countries, it proved challenging to attract stakeholders from the government authorities and state-owned utilities in the energy sector.

In the first workshop in both Ethiopia and Rwanda, stakeholders were initially asked to describe the current situation in terms of water and land-use for energy and food production and related socio-ecological impacts. This information was used to develop the initial reference scenario, also called "business-asusual” (BAU). In this scenario for both cases, all existing resource 


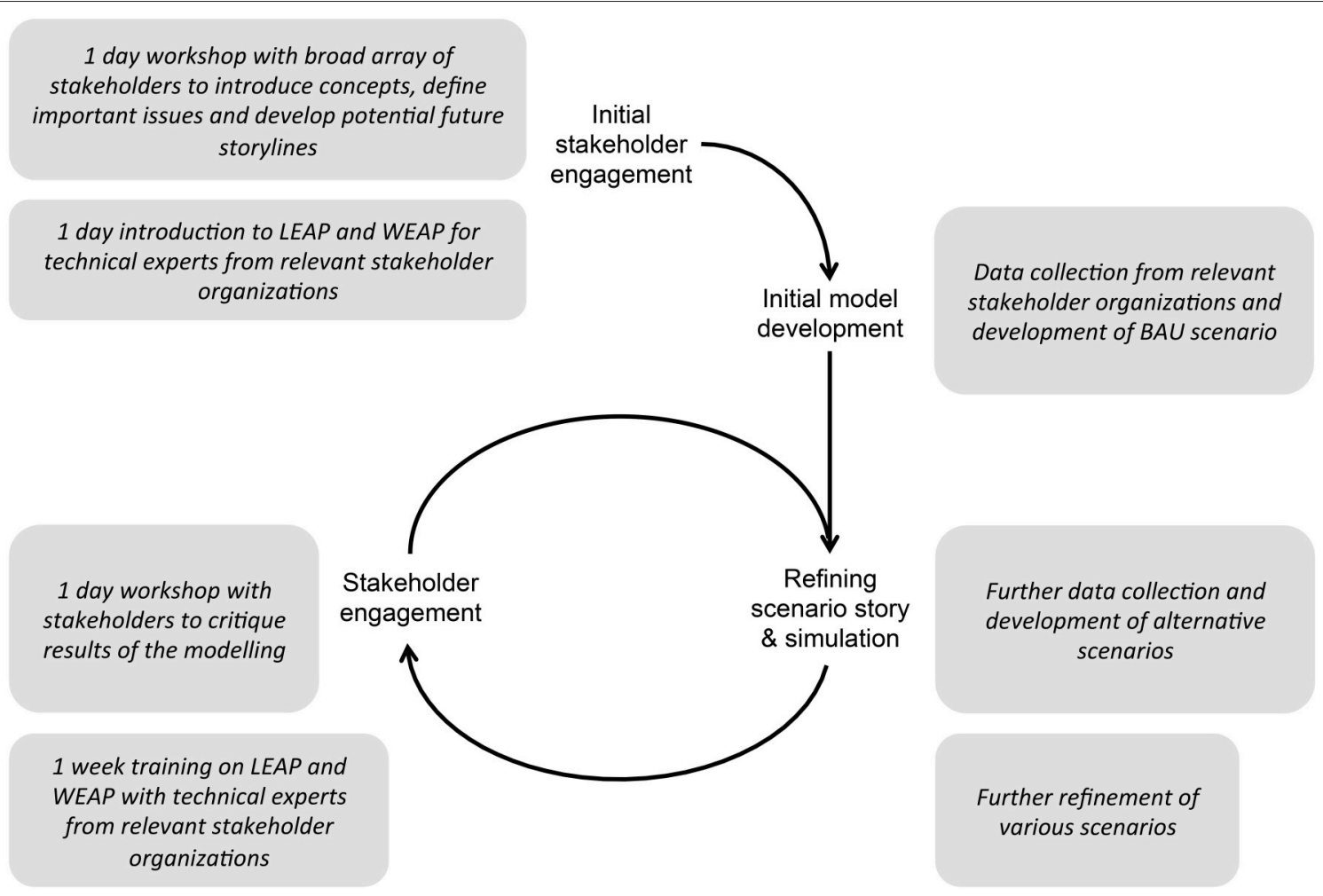

FIGURE 2 | Iterative participatory scenario planning in Ethiopia and Rwanda.

management practices were assumed to remain the same, or change according to historical trends, but distributed amongst a growing population as per expected growth patterns. In order to compare this BAU development pathway, the stakeholders were then asked to generate a second scenario based on the national policy framework. For example, population growth in Ethiopia and Rwanda were expected to continue at 3.1 and 2.5 per cent per year (the figure for Ethiopia is adopted in the specific case study area). Meanwhile, agricultural transformation in both countries would continue to unfold slowly and energy transition would remain hampered by continued dependence on traditional or marginally more efficient biomass energy.

Back-to-back with the first workshop, an initial training on the quantitative tools used in the projects (the "nexus tool-kit") was provided to the local technical team in each country. The intention was to engage experts early on to acquire knowledge on the tool-kit so that they could co-develop the application and be proficient users at the termination of the projects. Typically participants in this team were technically proficient junior/mid-level employees from stakeholder organizations, who may or may not already have prior knowledge of the modeling tools. In Ethiopia, the technical team for LEAP consisted of representatives of the Ethiopian Electric Power Company (EEPCo), the Environmental Protection, Land Administration and Use Bureau and the Mines and Energy Resources Development and Promotion Agency and Bahir Dar University. The technical team for WEAP included representatives from for instance the Bureau of Water Resource Development, the Bureau of Agriculture, the Abbay Basin Authority, the Amhara Regional Agricultural Research Institute (ARARI), and Bahir Dar University. In Rwanda, the technical team members came from for instance the Energy Utility Corporation, the Ministry of Infrastructure, the Ministry of Natural Resources, the Rwanda Natural Resources Authority, the Water and Sanitation Corporation, and a number of representatives from three districts specifically targeted in the study. In Ethiopia, it was particularly challenging to find energy experts. In Rwanda, energy experts were easier to access, but agricultural experts were difficult to access.

Based on the information gathered during the workshop, semi-structured interviews, local data-repositories made available by the stakeholders, and information found in the literature, a first model application was built using quantitative tools ("nexus tool-kit"). In our particular "nexus toolkit," we used the Water Evaluation and Planning (WEAP) tool ${ }^{3}$ and LEAP $^{4}$. These software tools are two of the most common water and energy planning tools used globally today, particularly in data scarce environments. In dialog with stakeholders, the tool can be applied to test classical "what if" questions (e.g., what if we increase the energy tariff, subsidize fertilizer, build more irrigation dams etc.). SEI's WEAP and LEAP "nexus toolkit" are

\footnotetext{
${ }^{3}$ http://sei-us.org/software/weap.

${ }^{4} \mathrm{http}: / /$ sei-us.org/software/leap.
} 
modeling tools that use a broad set of data collected in the field and from other sources. The toolkit can then analyse several development pathways, conduct stakeholder analysis of outputs and finally evaluate different development pathways.

\section{Refining Scenario Story and Simulation}

After the initial model application was completed by the modeling experts, a full-week training with the technical team was held in Ethiopia and Rwanda. During this week, the local application of the model was used as the training material. For instance, in Ethiopia the WEAP and LEAP model for the Lake Tana region was used. In Rwanda, a national level LEAP model was used and a WEAP model covering the Akagera basin was used. In this way, the technical team were given the opportunity to critique and refine the model assumptions and results-given their local knowledge - and were able to direct the modeling team to better or more appropriate data as necessary. In both cases, the technical training led to the emergence of invaluable and previously inaccessible reports and associated data on energy, water, and agriculture in the respective countries.

After a period of time, during which the model continued to be refined, a second workshop with the broader stakeholder group was then conducted (yet to be done in Rwanda). In Ethiopia, this workshop employed the use of the SWOT analysis approach (Strengths-Weaknesses-Opportunities-Threats). The SWOT analyses were complemented with questions about potential winners and losers under each scenario. The insights generated by these exercises thus highlighted the implications of each development trajectory for a variety of different stakeholder groups. Based on these implications, a set of unresolved dilemmas, also under the national framework scenario, were identified. As a response to this, the stakeholders defined a third scenario, hereafter called the "Nexus" scenario. As a result, the interaction between stakeholders and scientists in Ethiopia generated a revised set of narratives as well as a clearer understanding among the scientists on which data to include in the LEAP and WEAP models for the Lake Tana region.

\section{Co-exploring Scenario Impacts}

In consecutive workshops in Ethiopia, modeling work was analyzed and critiqued by the technical team, which led to a refinement of data and assumptions in an iterative process, until the results were deemed credible. In Rwanda, these workshops will take place in 2017 and 2018. The broader stakeholder group in the Lake Tana region participated in refining the scenarios and assessing impacts, again using SWOT analysis. The outcome of participatory scenario modeling work in Ethiopia was identification of clear, yet unresolved, conflicts and tradeoffs over national plans for water resource use in agriculture and energy and over current patterns of biomass resource use, as well as development of a "nexus" scenario that sought to address these conflicts and trade-offs (Karlberg et al., 2015a).

Overall, each step in the process can be iterated as necessary to further refine the models/scenarios, build competence within the technical team and increase dialog between stakeholders. When discussions move toward seeking solutions that address trade-offs, etc., then the process can be viewed as coming to a close. For instance, the dialog might lead to plans for several promising technical innovations that may have positive impacts for both transforming the agricultural and the energy sectors, such as micro-hydro schemes, bio-digesters, improved cookstoves, water harvesting dams, conservation agriculture, etc. If the both the direct and indirect impacts of upscaling these technologies are unclear, the "nexus tool-kit" can in these cases help to quantify the resources allocations to different sectors and potential environmental impacts, as well as the production of both food and energy for different development trajectories.

\section{DISCUSSION AND LESSONS LEARNED}

In order to further explore the conceptual approach demonstrated in this paper, we relate the process and methodology applied in the two case-studies in Ethiopia and Rwanda respectively with the rationales for participation (substantive, instrumental, and normative; Fiorino, 1990), and are thus able to confirm the relevance of all three in our proposed approach to scenario building in nexus studies. Furthermore, we provide a few concrete examples from each case-study as a way to illustrate how the water-energy-food nexus may play out in resources constrained, low-income countries in the tropics, with specific focus on charcoal.

\section{Local Knowledge}

The substantive argument for participatory nexus scenario planning emphasizes the importance of local knowledge and perceptions in fully understanding the water-energy-food security nexus in a particular context. During the initial interactions with the stakeholders a number of nexus issues that were of importance in the specific local setting were identified. In Ethiopia, our initial discussion revolved around water use for irrigation, hydropower generation, and maintaining environmental flow requirements in rivers and lakes. However, in subsequent workshops it became increasingly clear that biomass use for food, fodder, and fuel was just as important. Moreover, the use of water and biomass for energy and food production were strongly linked; current over-use of biomass for fodder and fuel was causing severe land-degradation and could only be partially offset by higher reliance on alternative energy sources such as electricity (e.g., hydropower). The analysis showed that if the management of biomass was to continue unchanged, demand would exceed supply by a factor of three by 2030 (Karlberg et al., 2015b), which has potentially severe implications for all sectors depending on biomass use, such as the charcoal industry and livestock rearing. Specifically, the demand for fuelwood, partly consisting of demand for charcoal, is predicted to exceed supply of woody biomass by a factor of five by 2030 , thus highlighting the urgent need to address the energy supply situation and specifically the cooking fuel component.

In Rwanda, the current overuse of biomass for charcoal production, and the governance implications thereof, was one of the entry points for discussion. Being severely constrained by productive land area, the country will need to make wellinformed decisions and come to agreement on how to best make use of this land and the associated biomass. As the charcoal sector 
currently employs a significant proportion of the population, such decisions need to be followed by a strategy for providing alternative sources of income for those that currently derive their livelihoods from this sector, should the decision be to reduce the dependence of charcoal in the energy sector in future. Such alternatives are currently being co-explored with the stakeholders and the research team in the on-going project in Rwanda.

As discussions developed, it became clear that the interactions between the processes of agricultural transformations and energy transitions was strong and complex and that there was a need for quantitative assessments to provide illustrations of different plausible development trajectories to support the planning of natural resources management which hitherto had been based on educated guesses on the developments of the other sectors, at best. Participatory scenario building can significantly contribute to a critical review of data on issues pertaining to the waterenergy-food nexus.

\section{Legitimacy}

The instrumental rationale for participatory scenario building revolves around the notion that decisions involving citizens are likely to be more legitimate. We found that the iterative process of model development and scenario refinement in Ethiopia and Rwanda helped to make the narratives significantly more relevant and appropriate from the perspective of the stakeholder groups. Moreover, by co-developing the local model application with a team of technical experts scrutinizing and contributing to data, assumptions and results, improved the quality of the application.

Also, past project experience shows that if local stakeholders can maintain a quantitative model, it has a better chance of informing decision-making. In this context a note of caution is warranted. Nexus analysis quickly becomes complex and is therefore resource consuming. Thus, before embarking on a fullscale nexus analysis, it is critical to hold an initial workshop and perform some initial sector specific quantifications of resource demand and supply to reveal if any nexus issues actually exist. It is important to remember that not everything is a nexus issue, and some issues can be managed more easily within a specific sector.

\section{Trade-Offs and Governance}

The normative drive for participation highlights the importance of stakeholder dialogue to clarify problems, identify unavoidable trade-offs and negotiate viable solutions to complex and uncertain environmental and societal problems associated with the nexus. The process highlights constraining and reinforcing interlinkages between different sectors and thus stimulates vital discussion between stakeholder groups who may not have discussed their separate future pathways with each other before. The projects brought together stakeholders from the food, water, energy, and environment sectors to discuss the implications of different development trajectories and to jointly develop new strategies that would address outstanding dilemmas. To support this dialogue, the co-creation of the scenarios and the joint analysis of the impacts resulted in a better understanding of the dilemmas facing each sector and hence a more common ownership of the development of the region by all stakeholders. Moreover, since the analysis was based on the data and assumptions made by the local experts, and provided a quantitative illustration of different development trajectories, the focus on the discussions was on impacts and options for resolving dilemmas, rather than arguing and guessing over resources availabilities. Even though there was often disagreement amongst the stakeholders on what constituted more or less desirable uses of resources, there was a shared understanding of that whatever each sector does will impact on the others. As a consequence, in Ethiopia all stakeholders expressed a need for continued dialogue to ensure cross-sector coherence. The outcome therefore was the forming of a cross sector platform for dialogue, and an improved understanding of joint issues pertaining to resource scarcity (in this case specifically water and biomass) and the needs of other sectors. The project also revealed gaps in the current policy framework that would need to be addressed to ensure a desirable future for all.

During the workshops in both Ethiopia and Rwanda, a lot of time was spent discussing which actors and/or institutions that have the mandate to govern nexus issues. This experience was also shared in a nexus rapid appraisal conducted in Zambia (Zur Heide et al., 2015). It appears that water management agencies have a central role to play, since they commonly have a mandate to plan water resources allocation amongst several stakeholders. Yet, they lack the land-use aspects and can also be said to have vested interests. On the other hand, most stakeholders did not suggest a new institution to take on the role of overseeing nexus issues. In this context, the issue of level is also important, i.e., should the nexus be managed a local, national or regional levels. It appears that most actors are present at the national level which is also where policies are being developed, so the national level will be, if not possibly the only level for nexus governance, so at least a critical one. In summary, we note that the ownership of the process is a challenge which has to be addressed in each specific local context.

\section{Challenges}

A number of outstanding challenges were also identified in both projects. Firstly, we note that actors sit at different levels at different sectors. For instance, in Ethiopia we conducted social network analyses on the agriculture, energy, water, and environment sectors (Stein, 2013). It was found that whilst agriculture, water and environment consisted of large actor networks ranging from the local to the national level, the energy network was smaller and most actors were concentrated at the national level. As a consequence, it was sometimes difficult to get participation by energy actors in workshops held at the local level. Moreover, despite the energy sector in Rwanda and Ethiopia being more than $80 \%$ biomass based (World Bank, 2009) the energy sector actors were predominantly focused on electricity. Since biomass scarcity is a major challenge and impacts greatly on land management, the lack of focus on bioenergy becomes problematic from a nexus perspective.

On a related note, it became clear during the stakeholder workshops that different stakeholders had different abilities to impact the decision on the ultimate use of resources. In Ethiopia for instance, stakeholders expressed that hydropower generation, 
followed by irrigation, took priority over meeting environmental flow requirements. We therefore identified a challenge to manage different power relations amongst actors in a nexus context.

Lastly, we note that implementing a cross-sector process inevitably takes time. Changing policy and planning processes normally takes longer than the duration of a research project. On the other hand, the uptake of quantitative tools to support the planning and decision-making process is faster. Overall, we conclude that the impacts of a nexus project are most likely experienced beyond the closing of the project, and therefore a strong local partner with a clear mandate to continue to support the process is critical to achieve long-term impacts.

\section{CONCLUSIONS}

The water-energy-food nexus concept takes an integrated approach to understanding ways in which human development can be pursued without adversely affecting natural resources and ecosystems. In this regard, the nexus approach has significant potential for exploring the barriers to and opportunities for sustainable production, trade and consumption of charcoal-an important and growing source of energy and income in subSaharan Africa. However, the complexities of the nexus require careful engagement with stakeholders to manage conflict and tensions around potential winners and losers of any future change or intervention.

In this conceptually-oriented paper, we proposed a participatory scenario-building process that facilitated engagement beyond technical aspects to include social, economic, and political concerns. Applying this participatory scenario-building process in empirical studies of the waterenergy-food nexus in Ethiopia and Rwanda, we found that such a process provides a valuable space for dialogues around development pathways that are sustainable both biophysically and socio-economically. Co-production and co-exploration of quantitative scenarios stimulates vital discussion between

\section{REFERENCES}

AfDB (2016). Feed Africa: Strategy for Agricultural Transformation in Africa 20162025. African Development Bank (AfDB), Abidjan, Côte d'Ivoire.

Africa Progress Panel (2015). Power People Planet: Seizing Africa's Energy and Climate Opportunities: Africa Progress Report 2015, Africa Progress Panel, Geneva.

Alcamo, J. (2008). Chapter six The SAS Approach: combining qualitative and quantitative knowledge in environmental scenarios. Dev. Integr. Environ. Assess. 2, 123-150. doi: 10.1016/S1574-101X(08)00406-7

Andersson, L., Olsson, J. A., Arheimer, B., and Jonsson, A. (2008). Use of participatory scenario modelling as platforms in stakeholder dialogues. Water SA Spec. HELP Ed. Spec. 34, 439-447. Available online at: http://www.scielo. org.za/scielo.php?script=sci_arttext\&pid=S1816-79502008000400003\&lng= en\&nrm=iso

Ansoms, A. (2008). A Green Revolution for Rwanda?: The Political Economy of Poverty and Agrarian Change. IOB, University of Antwerp.

Arnstein, S. R. (1969). A ladder of citizen participation. J. Am. Inst. Plann. 35, 216-224. doi: 10.1080/01944366908977225

Baard, P., Carlsen, H., Edvardsson Björnberg, K., and Vredin Johansson, M. (2011). Scenarios and Sustainability A Swedish Case Study of Adaptation Tools for Local stakeholder groups who may not have discussed their separate future pathways with each other before, and contributes to a shared understanding of how the sectors depend on each other, and therefore illustrates the need for joint solutions to outstanding dilemmas. We found that even though there was often disagreement amongst the stakeholders on what constituted more or less desirable development outcomes, there was a shared understanding of the interlinkages between the sectors and how those could be addressed. Our proposed methodology to participatory scenario building addressing the water-energy-food nexus highlights the relevance of substantive, instrumental, and normative rationales for stakeholder involvement.

Furthermore, we found that equipped with technical expertise and knowledge of how their sector fits into the broader socio-ecological landscape and system, stakeholders may be able to achieve more sustainable and equitable options to address resources allocation in the water-energy-food nexus. An outstanding challenge relates to the ownership of the processes and water-energy-food nexus related issues, which needs to adapt to local institutional structures and existing platforms for collaboration. Managing different power relations amongst stakeholders in yet another challenges which special relevance to the nexus, since by definition this topic involves an array of various actors.

\section{AUTHOR CONTRIBUTIONS}

Both authors co-wrote the paper; OJ led the organizing and writing and so was designated lead author.

\section{FUNDING}

The research in this paper is supported by the Swedish International Development Cooperation Agency (Sida) and Rwanda's Green Fund (FONERWA).
Decision-Makers. Working Paper No. 124. Stockholm: National Institute of Economic Research (NIER).

Bazilian, M., Rogner, H., Howells, M., Hermann, S., Arent, D., Gielen, D., et al. (2011). Considering the energy, water and food nexus: towards an integrated modelling approach. Energy Policy 39, 7896-7906. doi: 10.1016/j.enpol.2011.09.039

Bekele, M., and Girmay, Z. (2014). Reading through the Charcoal Industry in Ethiopia: Production, Marketing, Consumption and Impact (No. FSS Monograph No.9). Forum for Social Studies (FSS), Addis Ababa, Ethiopia.

Bierbaum, R., Stocking, M., Bouwman, H., Cowie, A., Diaz, S., Granit, J., et al. (2014). Delivering Global Environmental Benefits for Sustainable Development (No. Report to the 5th GEF Assembly, Mexico). Global Environment Facility, Washington, DC.

Bohunovsky, L., Jäger, J., and Omann, I. (2011). Participatory scenario development for integrated sustainability assessment. Reg. Environ. Change 11, 271-284. doi: 10.1007/s10113-010-0143-3

Bradfield, R., Wright, G., Burt, G., Cairns, G., and Van Der Heijden, K. (2005). The origins and evolution of scenario techniques in long range business planning. Futures 37, 795-812. doi: 10.1016/j.futures.2005. 01.003 
Carlsen, H., Dreborg, K. H., and Wikman-Svahn, P. (2013). Tailor-made scenario planning for local adaptation to climate change. Mitig. Adapt. Strateg. Glob. Change 18, 1239-1255. doi: 10.1007/s11027-012-9419-x

Chidumayo, E. N., and Gumbo, D. J. (2013). The environmental impacts of charcoal production in tropical ecosystems of the world: a synthesis. Energy Sustain. Dev. 17, 86-94. doi: 10.1016/j.esd.2012.07.004

CIA (2016). The World Factbook [WWW Document]. Available online at: https:// www.cia.gov/library/publications/the-world-factbook/ (Accessed December 13, 2016).

Drigo, R., Munyehirwe, A., Nzabanita, V., and Munyampundu, A. (2013). Final Report Update and Upgrade of WISDOM Rwanda and Woodfuels Value Chain Analysis as a Basis for the Rwanda Supply Master Plan for Fuelwood and Charcoal. Kigali: Rwanda Natural Resources Authority (RNRA).

Federal Democratic Republic of Ethiopia (2012). Ethiopia's Climate-Resilient Green Economy: Green Economy Strategy.

Fiorino, D. J. (1990). Citizen participation and environmental risk: a survey of institutional mechanisms. Sci. Technol. Hum. Values 15, 226-243. doi: $10.1177 / 016224399001500204$

Hallding, K., Nykvist, B., and Persson, Å. (2012). "The new geopolitics of environmental constraints, changing ecosystems and resources competition," in The Emerging Global Security Environment, Strategic Yearbook, ed B. Huldt (Stockholm: Swedish National Defence College), 301-330.

Harrison, S., and Mort, M. (1998). Which champions, which people? public and user involvement in health care as a technology of legitimation. Soc. Policy Admin. 32, 60-70. doi: 10.1111/1467-9515.00086

Hoff, H. (2011). "Understanding the Nexus," Presented at the Bonn 2011 Nexus Conference (Stockholm: Stockholm Environment Institute).

Howells, M., Hermann, S., Welsch, M., Bazilian, M., Segerström, R., Alfstad, T., et al. (2013). Integrated analysis of climate change, land-use, energy and water strategies. Nat. Clim. Change 3, 621-626. doi: 10.1038/nclimate1789

Interayamahanga, R. (2011). Citizen's Participation in Democratic Governance in Rwanda.

Jäger, J., and Patel, N. (2012). "An earth system perspective," in Fifth Global Environment Outlook: Environment for the Future We Want (Nairobi: United Nations Environment Programme).

Jones, L., and Carabine, E. (2013). Exploring political and socio-economic drivers of transformational climate policy: early insights from the design of ethiopia's climate resilient green economy strategy. Overseas Dev. Inst. Work Pap. doi: $10.2139 /$ ssrn. 2646522

Karlberg, L., Hoff, H., Amsalu, T., Andersson, K., Binnington, T., FloresLópez, F., et al. (2015a). Tackling complexity: understanding the foodenergy-environment nexus in Ethiopia's Lake tana sub-basin. Water Altern. 8, 710-734. Available online at: http://www.water-alternatives.org/index.php/ alldoc/articles/vol8/v8issue1/273-a8-1-6/file

Karlberg, L., Hoff, H., Flores-López, F., Goetz, A., and Matuschke, I. (2015b). Tackling biomass scarcity-from vicious to virtuous cycles in sub-Saharan Africa. Curr. Opin. Environ. Sustain. 15, 1-8. doi: 10.1016/j.cosust.2015.07.011

Kefale, A. (2011). The (un) making of opposition coalitions and the challenge of democratization in Ethiopia, 1991-2011. J. East. Afr. Stud. 5, 681-701. doi: 10.1080/17531055.2011.642525

Kok, K., Biggs, R., and Zurek, M. (2007). Methods for developing multiscale participatory scenarios: insights from southern Africa and Europe. Ecol. Soc. 13:8. doi: 10.5751/ES-01971-120108

Lee, B., Preston, F., Kooroshy, J., Bailey, R., and Lahn, G. (Eds.) (2012). Resources Futures. London: Royal Institute of International Affairs.

Matfess, H. (2015). Rwanda and Ethiopia: developmental Authoritarianism and the New Politics of African Strong Men. Afr. Stud. Rev. 58, 181-204. doi: 10.1017/asr.2015.43

Matthew, R. A., Barnett, J., McDonald, B., and O’Brien, K. L. (2010). Global Environmental Change and Human Security. Cambridge, MA: MIT Press.

Millennium Ecosystem Assessment (2005). Ecosystems and Human Well-Being. Washington, DC: Island Press.

Ministry of Finance and and Economic Development (2010). Growth and Transformation Plan 2010/11-2014/15, Vol. 2, Policy Matrix.

Mwampamba, T. H., Ghilardi, A., Sander, K., and Chaix, K. J. (2013). Dispelling common misconceptions to improve attitudes and policy outlook on charcoal in developing countries. Energy Sustain. Dev. 17, 75-85. doi: 10.1016/j.esd.2013.01.001
Nakicenovic, N., Alcamo, J., Davis, G., De Vries, B., Fenhann, J., Gaffin, S., et al. (2000). Special Report on Emissions Scenarios, Working Group III, Intergovernmental Panel on Climate Change (IPCC). Cambridge University Press, Cambridge, 595.

O’Neill, B. C., Kriegler, E., Ebi, K. L., Kemp-Benedict, E., Riahi, K., Rothman, D. S., et al. (2015). The roads ahead: Narratives for shared socioeconomic pathways describing world futures in the 21 st century. Glob. Environ. Change 42, 169-180. doi: 10.1016/j.gloenvcha.2015.01.004

Pahl-Wostl, C. (2002). Participative and stakeholder-based policy design, evaluation and modeling processes. Integr. Assess. 3, 3-14. doi: 10.1076/iaij.3.1.3.7409

Patel, M., Kok, K., and Rothman, D. S. (2007). Participatory scenario construction in land use analysis: an insight into the experiences created by stakeholder involvement in the Northern Mediterranean. Land Use Policy 24, 546-561. doi: 10.1016/j.landusepol.2006.02.005

Rahmato, D. (2011). Land to Investors: Large-Scale Land Transfers in Ethiopia. Forum for Social Studies, Addis Ababa.

Ravera, F., Hubacek, K., Reed, M., and Tarrasón, D. (2011). Learning from experiences in adaptive action research: a critical comparison of two case studies applying participatory scenario development and modelling approaches. Environ. Policy Gov. 21, 433-453. doi: 10.1002/ eet.585

Reed, M. S., Kenter, J., Bonn, A., Broad, K., Burt, T. P., Fazey, I. R., et al. (2013). Participatory scenario development for environmental management: a methodological framework illustrated with experience from the UK uplands. J. Environ. Manage. 128, 345-362. doi: 10.1016/j.jenvman.2013. 05.016

Republic of Rwanda (2007). Economic Development and Poverty Reduction Strategy: 2008-2012. Kigali.

Republic of Rwanda (2011). Green Growth and Climate Resilience: National Strategy for Climate Change and Low Carbon Development.

Republic of Rwanda (2013). Economic Development and Poverty Reduction Strategy II: 2013-2018.

Robinson, J., Burch, S., Talwar, S., O'Shea, M., and Walsh, M. (2011). Envisioning sustainability: recent progress in the use of participatory backcasting approaches for sustainability research. Technol. Forecast. Soc. Change 78, 756-768. doi: 10.1016/j.techfore.2010.12.006

Rounsevell, M. D., and Metzger, M. J. (2010). Developing qualitative scenario storylines for environmental change assessment. Wiley Interdiscip. Rev. Clim. Change 1, 606-619. doi: 10.1002/wcc.63

Spielmann, M., Scholz, R., Tietje, O., and de Haan, P. (2005). Scenario modelling in prospective LCA of transport systems. Application of Formative scenario analysis (11 pp). Int. J. Life Cycle Assess. 10, 325-335. doi: $10.1065 /$ lca2004.10.188

Stein, C. (2013). How Understanding Social Networks Can Help to Govern the Nexus: a Case from the Blue Nile Basin, SEI Discussion Brief. Stockholm: Stockholm Environment Institute.

Stirling, A. (2007). "Opening Up" and "Closing Down": Power, Participation, and Pluralism in the social appraisal of technology. Sci. Technol. Hum. Values 33, 262-294. doi: 10.1177/0162243907311265

Swart, R., Raskin, P., and Robinson, J. (2004). The problem of the future: sustainability science and scenario analysis. Glob. Environ. Change 14, 137-146. doi: 10.1016/j.gloenvcha.2003.10.002

The Economist (2010). Efficiency versus Freedom. The Economist. Available online at: http://www.economist.com/node/16743333

United Nations (2013). Women Secure 64 Per Cent of Seats in Rwandan Parliamentary Elections | ONE UN Rwanda [WWW Document]. Available online at: http://www.rw.one.un.org/press-center/news/women-secure-64cent-seats-rwandan-parliamentary-elections (Accessed November 9, 2016).

Uvin, P. (2001). Difficult choices in the new post-conflict agenda: the international community in Rwanda after the genocide. Third World Q. 22, 177-189. doi: 10.1080/01436590120043291

van Vliet, M., Kok, K., and Veldkamp, T. (2010). Linking stakeholders and modellers in scenario studies: the use of Fuzzy Cognitive Maps as a communication and learning tool. Futures 42, 1-14. doi: 10.1016/j.futures.2009.08.005

Verhoeven, H. (2011). Black Gold for Blue Gold?: Sudan's Oil, Ethiopia's Water and Regional Integration. Chatham House. 
Voinov, A., and Bousquet, F. (2010). Modelling with stakeholders. Environ. Model. Softw. 25, 1268-1281. doi: 10.1016/j.envsoft.2010.03.007

Voinov, A., and Gaddis, E. J. B. (2008). Lessons for successful participatory watershed modeling: a perspective from modeling practitioners. Ecol. Model. 216, 197-207. doi: 10.1016/j.ecolmodel.2008. 03.010

Volkery, A., Ribeiro, T., Henrichs, T., and Hoogeveen, Y. (2008). Your Vision or My Model? Lessons from participatory land use scenario development on a European Scale. Syst. Pract. Action Res. 21, 459-477. doi: 10.1007/s11213-008-9104-x

World Bank (2009). The Little Data Book on Africa 2008/2009. Washington, DC: The World Bank.

Zulu, L. C., and Richardson, R. B. (2013). Charcoal, livelihoods, and poverty reduction: evidence from sub-Saharan Africa. Energy Sustain. Dev. 17, 127-137. doi: 10.1016/j.esd.2012.07.007
Zur Heide, F., Woltering, L., Karlberg, L., and Weitz, N. (2015). Rapid appraisal of the Water-Energy-Food nexus in Zambia (No. Discussion Brief). GFA Consulting Group GmbH/Stockholm Environment Institute (SEI), Hamburg and Stockholm.

Conflict of Interest Statement: The authors declare that the research was conducted in the absence of any commercial or financial relationships that could be construed as a potential conflict of interest.

Copyright $\odot 2017$ Johnson and Karlberg. This is an open-access article distributed under the terms of the Creative Commons Attribution License (CC BY). The use, distribution or reproduction in other forums is permitted, provided the original author(s) or licensor are credited and that the original publication in this journal is cited, in accordance with accepted academic practice. No use, distribution or reproduction is permitted which does not comply with these terms. 